\title{
Pengaruh Perubahan Tataguna Lahan Jalan Raya Tomohon-Manado Terhadap Daya Dukung Tanah
}

\author{
Morris S.S.S. Tumanduk ${ }^{1}$ \\ Universitas Negeri Manado \\ e-mail: morristumanduk@gmail.com \\ Toar U. Y. Pangkey ${ }^{2}$ \\ Universitas Negeri Manado \\ Rulyanto G. M. Lasut ${ }^{3}$ \\ Universitas Negeri Manado
}

\begin{abstract}
ABSTRAK
Pemanfaatan lahan yang tidak sesuai dengan kelas kesesuaiannya akan memberikan dampak buruk, baik secara fisik maupun ekonomi. Secara fisik, pemanfaatan lahan yang tidak sesuai dengan daya dukung lahan dapat menimbulkan kerusakan lahan (Mather, 1986) dan sebaliknya, penggunaan lahan yang tepat adalah langkah pertama untuk menunjang program konservasi lahan (Sinukaban, 1989). Adapun secara ekonomi, ketidaksesuaian lahan akan berdampak pada produktivitas lahan. Jalan Tomohon - Manado adalah jalan Arteri Primer atau jalan nasional yang menghubungkan antar provinsi berdasarkan Peraturan Daerah Provinsi Sulawesi Utara Nomor 1 Tahun 2014 Tentang Rencana Tata Ruang Wilayah Provinsi Sulawesi Utara Tahun 2014 - 2034. Jalan Raya Tomohon - Manado merupakan salah satu jalan regional utama yang menghubungkan wilayah Manado, Minahasa, dan Tomohon serta mendukung pertumbuhan ekonomi di Sulawesi Utara, maupun daerah sekitarnya. Adanya pemukiman berupah bangunan rumah tinggal, restoran, resting area, dan hotel di sepanjang jalan Tomohon - Manado merupakan perubahan tata guna lahan, lokasi tersebut terletak di lereng bukit yang terjal, rawan terhadap bencana tanah longsor. Pemerintah Kota Tomohon sudah berupaya membatasi pemanfaatan ruang di kawasan rawan bencana terhadap kegiatan pemukiman. Namun kenyataannya, masih ada pemanfaatan lahan di daerah rawan tanah longsor dan pemerintah daerah belum dapat menerapkan kebijakan tersebut secara optimal, hal tersebut dikarenakan sebagian besar penduduk sudah lama bermukim di daerah rawan bencana bahkan sudah ada yang turun-temurun. Hal ini menyulitkan pemerintah daerah untuk melakukan penataan pemanfaatan lahan pada kawasan rawan bencana alam tanah longsor. Salah satu kejadian tanah longsor yang terjadi pada Tanggal 15 Januari 2014 di sepanjang jalan Tomohon - Manado. Berdasarkan bentuk dan struktur topografi lokasi jalan Tomohon Manado, pemanfaatan lahan tidak layak untuk membangun rumah tinggal, restoran, resting area, dan hotel, karena sangat mempengaruhi ketidakstabilan lereng sehingga dapat mengurangi daya dukung tanah.
\end{abstract}

\section{Kata kunci: Jalan Tomohon-Manado, Tataguna Lahan, Daya Dukung Tanah}

\section{ABSTRACT}

Land use that is inconsistent with its suitability class will adversely affect both physically and economically. Physically, land use that is inconsistent with the carrying capacity of the land can cause land damage (Mather, 1986) and vice versa, appropriate land use is the first step to support the land conservation program (Sinukaban, 1989). As for the economy, land mismatch will have an impact on land productivity. Tomohon Street - Manado is a primary arterial road or national road connecting between provinces based on North Sulawesi Provincial Regulation No. 1 of 2014 Concerning North Sulawesi Province Spatial Planning Year 2014-2034. Tomohon Highway - Manado is one of the main regional roads connecting the areas of Manado, Minahasa, and Tomohon as well as supporting economic growth in North Sulawesi, as well as the surrounding areas. The existence of a residential

Jurnal Frontiers Volume 1 Nomor 1, April 201857

P-ISSN: 2621-0991 E-ISSN: 2621-1009 
M. S. S. S. Tumanduk ${ }^{1}$, T. U. Y. Pangkey ${ }^{2}$, Jurnal Sains dan Teknologi, Universitas Negeri Manado

wage of residential buildings, restaurants, resting areas and hotels along Tomohon - Manado road is a land use change, the location is located on a steep hillside, prone to landslide disaster. Tomohon City Government has been trying to limit the use of space in disaster prone areas to residential activities. But in reality, there is still land use in landslide prone areas and local governments have not been able to implement the policy optimally, it is because most of the population has long been living in disaster prone areas even existing for generations. This makes it difficult for local governments to conduct land use arrangements in areas prone to natural disasters landslides. One of the occurrences of landslides that occurred on January 15, 2014 along the road Tomohon - Manado. Based on the shape and topographic structure of Tomohon - Manado road location, land use is not feasible to build houses, restaurants, resting areas, and hotels, because it greatly affects the slope instability so as to reduce soil bearing capacity.

\section{Keywords: Tomohon-Manado Road, Land Use, Land Supporting Capacity}

\section{PENDAHULUAN}

Perkembangan suatu wilayah akan meningkatkan kebutuhan lahan sebagai tempat tinggal dan beraktivitas ekonomi, adapun ketersediaan lahan yang ada tidak mengalami perkembangan. Penduduk terpaksa menempati lokasi yang tidak layak huni seperti di daerah perbukitan dan lereng pegunungan. Aktivitas masyarakat tersebut menyebabkan tingkat kerawanan bencana menjadi semakin meningkat, manakala lahan dieksploitasi secara berlebihan tanpa memperhatikan daya dukung tanah. Ketersediaan informasi yang lengkap dan akurat mengenai pengendalian pemanfaatan lahan di kawasan rawan tanah longsor beserta peraturan yang bisa dijadikan dasar dalam setiap aktivitas pengembangan merupakan hal yang sangat diperlukan demi mencegah dan meminimalkan korban jiwa dan dampak ekonomi yang ditimbulkan oleh bencana alam tanah longsor.

Tanah longsor adalah suatu peristiwa alam yang pada saat ini frekuensi kejadiannya semakin meningkat. Fenomena alam ini berubah menjadi bencana alam tanah longsor yang menimbulkan korban baik berupa korban jiwa maupun kerugian harta benda. Indonesia yang sebagian wilayahnya berupa daerah perbukitan dan pegunungan, menyebabkan sebagian wilayah Indonesia menjadi daerah yang rawan kejadian tanah longsor. Intensitas curah hujan yang tinggi dan kejadian gempa yang sering muncul, secara alami akan dapat memicu terjadinya bencana alam tanah longsor. Kekuatan tanah tergantung dari ikatan antara partikel penyusun tanah, sedangkan untuk batuan lebih banyak ditentukan oleh retakan pada batuan itu. Air hujan dalam jumlah yang kecil menyebabkan tanah menjadi lembab dan mempunyai efek memperkuat tanah, namun apabila tanah menjadi jenuh air efeknya akan melemahkan ikatan partikel. Molekul air menyusup ke partikel tanah dan menjadi katalisator proses gelinciran antara partikel. Faktor ini yang menyebabkan tanah longsor banyak terjadi pada musim penghujan. Faktor penyebab lainnya yaitu pendayagunaan sumberdaya alam secara tidak teratur atau melampaui daya dukungnya akan memicu terjadinya bencana. Nilai suatu lahan yang rendah atau mempunyai kondisi geologi dan jenis medan yang kurang baik jika tidak diperhatikan secara cermat dalam perluasan lahan usahanya, akan mengundang bencana alam tanah longsor (Verstappen, 1983).

Jalan Raya Tomohon-Manado yang terletak di wilayah Kelurahan Tinoor Dua Kecamatan Tomohon Utara Kota Tomohon dan di wilayah Desa Warembungan Kecamatan Pineleng Kabupaten Minahasa sepanjang kurang lebih $7 \mathrm{KM}$ terdapat bangunan rumah penduduk dan rumah makan. Lokasi tersebut terletak di lereng bukit yang terjal, rawan terhadap bencana tanah longsor.

Berdasarkan uraian diatas, maka penulis tertarik untuk mengadakan penelitian dengan judul: "Pengaruh Perubahan Tataguna Lahan

Jurnal Frontiers Volume 1 Nomor 1, April 201858

P-ISSN: 2621-0991 E-ISSN: 2621-1009 
Jalan Raya Tomohon - Manado Terhadap Daya Dukung Tanah".

Adapun yang menjadi tujuan dalam penelitian ini adalah :

1. Untuk mengetahui kondisi fisik alam, sosial ekonomi, pemahaman masyarakat terhadap kondisi lingkungan dan penyebab pemanfaatan lahan pada Jalan Raya Tomohon - Manado.

2. Untuk mengetahui bagaimana perubahan tataguna lahan Jalan Raya Tomohon Manado terhadap daya dukung tanah.

Adapun yang menjadi manfaat dalam penelitian ini adalah:

1. Untuk menjadikan salah satu masukan bagi penulis sebagai Staff Pengajar di Jurusan Pendidikan Teknik Bangunan Program Studi Teknik Sipil Fakultas Teknik Universitas Negeri Manado dalam Pengembangan Mutu Pendidikan khususnya Mata Kuliah Geologi Teknik dan Mekanika Tanah.

2. Dapat dijadikan salah satu acuan dalam meningkatkan mutu pendidikan di Jurusan Pendidikan Teknik Bangunan Program Studi Teknik Sipil Fakultas Teknik Universitas Negeri Manado pada khususnya dan di Universitas Negeri Manado pada umumnya.

3. Memberikan rekomendasi kepada Pemerintah Kota Tomohon dan Kabupaten Minahasa dalam pemanfaatan lahan yang ada khususnya hasil aktivitas manusia baik berupa permukiman, lahan pertanian dan infrastruktur yang lain, untuk mencegah terjadinya bencana alam.

\section{METODE}

Lokasi yang digunakan sebagai objek penelitian adalah sepanjang Jalan Raya Tomohon-Manado yang terletak di wilayah Kelurahan Tinoor Kecamatan Tomohon Utara Kota Tomohon dan wilayah Desa Warembungan Kecamatan Pineleng Kabupaten Minahasa.

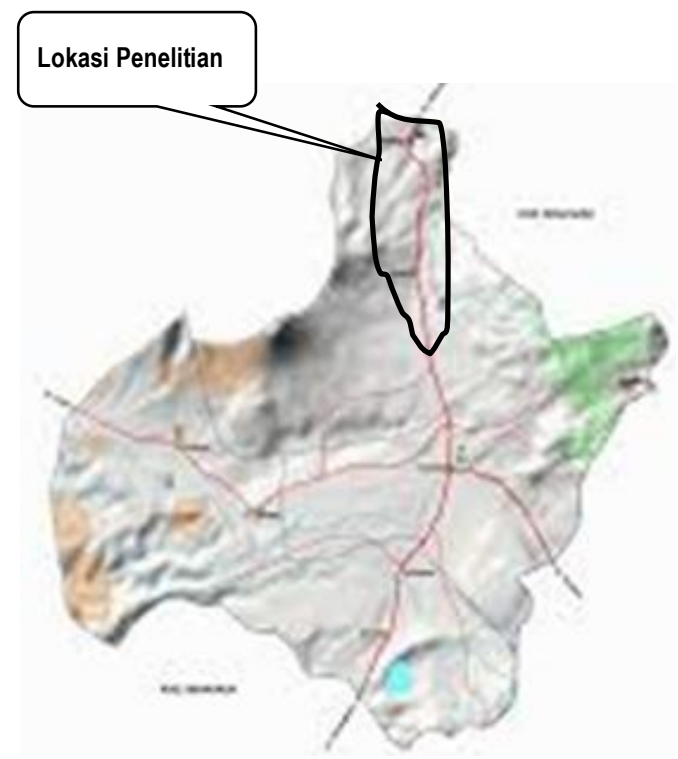

Gambar 1. Peta Lokasi Penelitian

Penelitian ini dilaksanakan di sepanjang Jalan Raya Tomohon-Manado yang terletak di wilayah Kelurahan Tinoor Kota Tomohon dan wilayah Desa Warembungan Kecamatan Pineleng Kabupaten Minahasa sepanjang kurang lebih $9 \mathrm{KM}$, dengan jangka waktu selama 4 bulan.

Pada tahap persiapan kegiatan yang dilakukan adalah studi pustaka dan studi peta geologi regional. Studi pustaka akan memberikan gambaran mengenai teori-teori yang berhubungan dengan gerakan tanah dan memperoleh gambaran terhadap metode yang akan digunakan dalam penelitian. Studi peta geologi regional dapat mengetahui secara regional litologi, stratigrafi, struktur geologi, sosial, dan ekonomi daerah penelitian. Pada tahap ini dilakukan juga persiapan-persiapan meliputi administrasi, peralatan dan bahan untuk pekerjaan di lapangan.

Data yang diperlukan untuk penulisan penelitian berupa data primer dan data skunder. Data primer adalah data yang di ambil langsung dari hasil investigasi lapangan dan data hasil penyelidikan sampel tanah di laboratorium. Data sekunder adalah data yang sudah ada sebelumnya sebagai pendukung untuk memberikan informasi yang jelas 
mengenai kondisi lapangan dan sebagai acuan untuk proses analisa dan pembahasan.

Data yang di peroleh di lapangan dipadukan dengan data observasi laboratorium, kemudian diolah. Hasil-hasil yang diperoleh adalah sebagai berikut.

1. Faktor penyebab perubahan tataguna lahan,

2. Faktor penyebab terjadinya longsoran

3. Mekanisme longsoran,

4. Analisis stabilitas lereng,

5. Cara penanggulangan.

Hasil penelitian disajikan dalam bentuk informasi berupa peta rawan bencana tanah longsor pada daerah penelitian dan metode tataguna lahan. Disamping itu, disampaikan pula laporan hasil kajian secara lengkap penyebab perubahan tataguna lahan dan penyebab tanah longsor di Jalan Raya Tomohon-Manado.

\section{HASIL DAN PEMBAHASAN Deskripsi Lokasi Penelitian}

Pelaksanaan penelitian merupakan lahan yang rawan terjadinya gerakan tanah / tanah longsor, maka pengamatan secara mendetail telah dilakukan terhadap kondisi lahan di lokasi tersebut. Untuk mengetahui kondisi lapisan tanah telah dilakukan investigasi lapangan. Penyelidikan tanah secara umum bertujuan untuk mendapatkan informasi mengenai kondisi dan karakteristik lapisan tanah di lokasi pengujian.

Pada dasarnya daerah perbukitan atau pegunungan yang membentuk lahan miring merupakan daerah rawan terjadi gerakan tanah. Kelerengan dengan kemiringan lebih dari $20^{\circ}$ (atau sekitar 40\%) memiliki potensi untuk bergerak atau longsor, namun tidak selalu lereng atau lahan yang miring punya potensi untuk longsor tergantung dari kondisi geologi yang bekerja pada lereng tersebut, Karnawati, (2003) menjelaskan bahwa dari beberapa kajian terhadap kejadian longsor dapat teridentifikasi tiga tipologi lereng yang rentan untuk bergerak/longsor, yaitu:
1. Lereng yang tersusun oleh tumpukan tanah residu yang dialasi oleh batuan atau tanah yang lebih kompak;

2. Lereng yang tersusun oleh perlapisan batuan yang miring searah kemiringan lereng maupun berlawanan dengan kemiringan lereng;

3. Lereng yang tersusun oleh blok-blok batuan.

Kemiringan lereng dari suatu daerah merupakan salah satu faktor penyebab terjadinya gerakan tanah seperti pada Tabel 1 .

Tabel 1. Klasifikasi Lereng

\begin{tabular}{cccc}
\hline No & $\begin{array}{c}\text { Kelerengan } \\
(\%)\end{array}$ & Deskripsi & Satuan Morfologi \\
\hline 1 & $\mathbf{0 - 8}$ & Datar & Dataran \\
\hline 2 & $\mathbf{8 - 1 5}$ & Landai & $\begin{array}{c}\text { Perbukitan berelief } \\
\text { halus }\end{array}$ \\
\hline 3 & $\mathbf{1 5 - 2 5}$ & $\begin{array}{c}\text { Agak } \\
\text { Curam }\end{array}$ & $\begin{array}{c}\text { Perbukitan berelief } \\
\text { sedang }\end{array}$ \\
\hline 4 & $\mathbf{2 5 - 4 5}$ & Curam & $\begin{array}{c}\text { Perbukitan berelief } \\
\text { kasar }\end{array}$ \\
\hline 5 & $\mathbf{> 4 5}$ & $\begin{array}{c}\text { Sangat } \\
\text { Curam }\end{array}$ & $\begin{array}{c}\text { Perbukitan berelief } \\
\text { sangat kasar }\end{array}$ \\
\hline
\end{tabular}

Sumber : van Zuidam (1983)

Topografi lokasi penelitian merupakan daerah perbukitan atau pegunungan yang membentuk lahan miring, dengan kemiringan rata-rata dari $35^{\circ}-75^{\circ}$, seperti pada Gambar 2

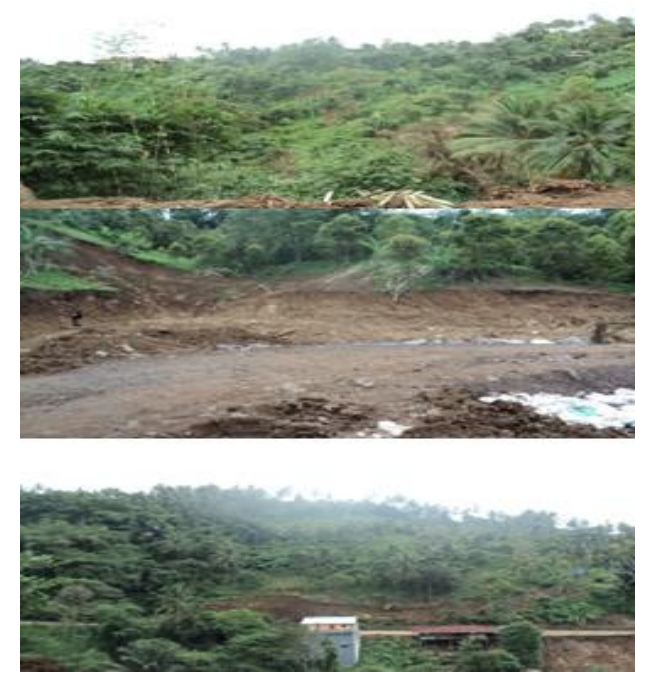

Gambar 2. Foto Topografi Lokasi Penelitian 
Potensi terjadinya gerakan tanah pada lereng tergantung pada kondisi tanah dan batuan penyusunnya, dimana salah satu proses geologi yang menjadi penyebab utama terjadinya gerakan tanah adalah pelapukan batuan, Selby (1993).

Berdasarkan analisis di lokasi penelitian lapisan tanah lempung warna kecoklatan sifat kenyal berada di antara elevasi $-0,00 \mathrm{~m}$ sampai dengan $-1,50 \mathrm{~m}$, lapisan tanah lempung berpasir dan berbatu warna coklat kekuningan sifat lepas berada di antara elevasi -1,50 m sampai dengan $-3,00 \mathrm{~m}$, Lapisan tanah batu lempung warna coklat kehitaman sifat lepas berada di antara elevasi $-3,00 \mathrm{~m}$ sampai dengan $-5,00 \mathrm{~m}$.

Proses pelapukan batuan yang sangat intensif banyak dijumpai di negara-negara yang memiliki iklim tropis seperti Indonesia. Tingginya intensitas curah hujan dan penyinaran matahari menjadikan proses pelapukan batuan lebih intensif. Batuan yang banyak mengalami pelapukan akan menyebabkan berkurangnya kekuatan batuan yang pada akhirnya membentuk lapisan batuan lemah dan tanah residu yang tebal. Apabila hal ini terjadi pada lereng maka lereng akan menjadi kritis.

Curah hujan akan meningkatkan presepitasi dan kejenuhan tanah serta naiknya muka air tanah. Jika hal ini terjadi pada lereng dengan material penyusun (tanah dan atau batuan) yang lemah maka akan menyebabkan berkurangnya kuat geser tanah/batuan dan menambah berat massa tanah, pada dasarnya ada dua tipe hujan pemicu terjadinya longsor, yaitu hujan deras yang mencapai $70 \mathrm{~mm}$ hingga $100 \mathrm{~mm}$ perhari dan hujan kurang deras namun berlangsung menerus selama beberapa jam hingga beberapa hari yang kemudian disusul dengan hujan deras sesaat. Pada lereng longsoran dapat terjadi pada bulan-bulan awal musin hujan, sekitar awal Desember atau awa Januaril.

Pada awal Januari 2014 terjadi curah hujan deras hingga mencapai kurang lebih $100 \mathrm{~mm}$ perhari, sampai puncaknya pada tanggal 15 Januari 2014 telah terjadi bencana tanah longsor, yang mengakibatkan 6 korban jiwa dan kerugian harta benda berupa 7 bangunan rumah serta 5 kendaraan mobil dan 15 kendaraan sepeda motor yang tertimbun tanah longsor di wilayah Kelurahan Tinoor Kecamatan Tomohon Utara Kota Tomohon sepanjang kurang lebih $3 \mathrm{KM}$.

Faktor geologi lainnya yang menjadi pemicu terjadinya gerakan tanah adalah aktivitas volkanik dan tektonik. Faktor geologi dapat dianalisis melalui variabel tekstur tanah dan jenis batuan. Tekstur tanah dan jenis batuan merupakan salah satu faktor penyebab terjadinya gerakan tanah yang diukur berdasarkan sifat tanah dan kondisi fisik batuan. Daerah lokasi penelitian berada di bawah kaki Gunung Lokon.

\section{Perubahan Tata Guna Lahan Jalan Tomohon - Manado}

Pengembangan wilayah adalah upaya terpadu untuk memacu perkembangan sosial ekonomi, mengurangi kesenjangan antar wilayah dan menjaga kelestarian lingkungan hidup pada suatu wilayah. Pengembangan wilayah sangat diperlukan karena setiap wilayah memiliki karakteristik yang sangat berbeda (Riyadi, 2002). Dalam konteks pengembangan wilayah, dimensi ruang memiliki arti penting karena ruang dapat membawa kemajuan dan juga menciptakan konflik bagi individu dan masyarakat (Riyadi, 2002). Ruang menjadi rebutan karena ketersediaannya semakin langka dan terbatas. Ruang adalah wadah tempat manusia dan makhluk hidup lainnya hidup dan melakukan kegiatan serta memelihara 
kelangsungan hidupnya; ruang mencakup lahan dengan berbagai sumberdaya yang ada di atas maupun di dalamnya. Bertentangan dengan ketersediaannya yang semakin terbatas, kebutuhan terhadap lahan justru semakin meningkat dengan peningkatan jumlah penduduk dan kegiatan pembangunan. Apalagi lahan juga perlu dikonservasi untuk penggunaannya di masa mendatang (Sitorus, 1995). Terkait dengan kondisi lahan yang terbatas, pemanfaatan lahan harus dilakukan secara terencana, rasional, optimal dan bertanggungjawab serta sesuai dengan kemampuan daya dukungnya (Sugandhy, 1999).

Pemanfaatan lahan yang tidak sesuai dengan kelas kesesuaiannya akan memberikan dampak buruk, baik secara fisik maupun ekonomi. Secara fisik, pemanfaatan lahan yang tidak sesuai dengan daya dukung lahan dapat menimbulkan kerusakan lahan (Mather, 1986) dan sebaliknya, penggunaan lahan yang tepat adalah langkah pertama untuk menunjang program konservasi lahan (Sinukaban, 1989). Adapun secara ekonomi, ketidaksesuaian lahan akan berdampak pada produktivitas lahan.

Jalan Tomohon - Manado adalah jalan Arteri Primer atau jalan nasional yang menghubungkan antar provinsi berdasarkan Peraturan Daerah Provinsi Sulawesi Utara Nomor 1 Tahun 2014 Tentang Rencana Tata Ruang Wilayah Provinsi Sulawesi Utara Tahun 2014 2034. Jalan Raya Tomohon - Manado merupakan salah satu jalan regional utama yang menghubungkan wilayah Manado, Minahasa, dan Tomohon serta mendukung pertumbuhan ekonomi di Sulawesi Utara, maupun daerah sekitarnya. Kemacetan terus mewarnai jalan Raya TomohonManado, disamping karena padatnya arus lalu lintas, juga di sebabkan faktor sempitnya jalan di beberapa titik, juga menjadi penyebab terjadinya macet, karena antrian kendaraan yang silih berganti melintasi jalan tersebut. Dengan kondisi jalan seperti ini tentunya sangat menggangu kenyaman pengguna jalan yang melintasi jalan Tomohon- Manado, apalagi menjelang perayaan Natal dan Tahun Baru, arus lalulintas di jalur tersebut di pastikan akan sangat padat.

Adanya pemukiman berupah bangunan rumah tinggal, restoran, resting area, dan hotel di sepanjang jalan Tomohon-Manado merupakan perubahan tata guna lahan, lokasi tersebut terletak di lereng bukit yang terjal, rawan terhadap bencana tanah longsor. Pemerintah Kota Tomohon sudah berupaya membatasi pemanfaatan ruang di kawasan rawan bencana terhadap kegiatan pemukiman. Namun kenyataannya, masih ada pemanfaatan lahan di daerah rawan tanah longsor dan pemerintah daerah belum dapat menerapkan kebijakan tersebut secara optimal, hal tersebut dikarenakan sebagian besar penduduk sudah lama bermukim di daerah rawan bencana bahkan sudah ada yang turun-temurun. Hal ini menyulitkan pemerintah daerah untuk melakukan penataan pemanfaatan lahan pada kawasan rawan bencana alam tanah longsor. Salah satu kejadian tanah longsor yang terjadi pada Tanggal 15 Januari 2014 di sepanjang jalan Tomohon - Manado seperti pada Gambar 3

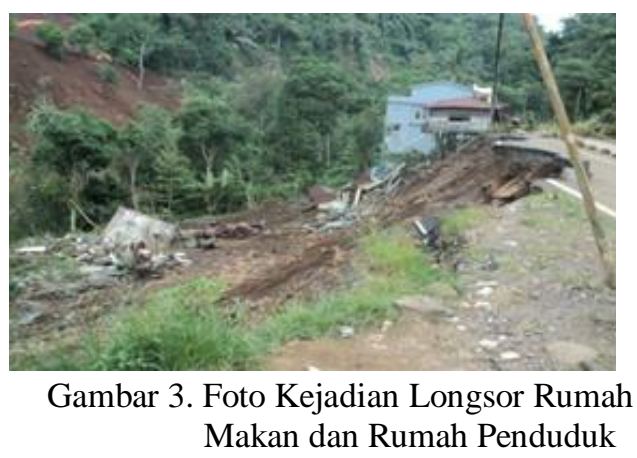


M. S. S. S. Tumanduk ${ }^{1}$, T. U. Y. Pangkey ${ }^{2}$, Jurnal Sains dan Teknologi, Universitas Negeri Manado

Adanya ketidakstabilan tanah di sepanjang jalan Tomohon - Manado dapat memberikan pengaruh yang bervariasi tergantung pada besarnya daya dukung tanah dan jangkauan dari kawasan tanah longsor tersebut. Bencana alam tanah longsor ini sifatnya sulit dideteksi dan dipredikasi kapan akan terjadi dan sampai kapan kejadian akan berlangsung, maka usaha untuk menghindari bencana tersebut mengalami kesulitan untuk dilaksanakan. Suatu pemukiman baru tidak selalu terdapat pada lokasi lahan yang ideal sesuai dengan tata guna lahan yang telah ditetapkan, beberapa faktor dapat berpengaruh terhadap lokasi lahan ini, seperti jalur gempa bumi, jalur ketidakstabilan lereng atau terdapatnya zona longsoran.

Berdasarkan bentuk dan struktur topografi lokasi jalan Tomohon - Manado, pemanfaatan lahan tidak layak untuk membangun rumah tinggal, restoran, resting area, dan hotel, karena sangat mempengaruhi ketidakstabilan lereng sehingga dapat mengurangi daya dukung tanah.

\section{PENUTUP}

\section{Kesimpulan}

Berdasarkan hasil analisis, maka dari penelitian ini dapat ditarik beberapa kesimpulan sebagai berikut ini:

1. Topografi lokasi penelitian merupakan daerah perbukitan atau pegunungan yang membentuk lahan miring, dengan kemiringan rata-rata dari $35^{\circ}-75^{\circ}$ dan tersusun oleh tumpukan tanah residu yang dialasi oleh batuan atau tanah yang lebih kompak memiliki potensi untuk bergerak atau longsor.

2. Jalan Tomohon - Manado adalah jalan Arteri Primer atau jalan nasional yang menghubungkan antar provinsi berdasarkan Peraturan Daerah Provinsi Sulawesi Utara Nomor 1 Tahun 2014
Tentang Rencana Tata Ruang Wilayah Provinsi Sulawesi Utara Tahun 2014 2034.

3. Jalan Raya Tomohon - Manado merupakan salah satu jalan regional utama yang menghubungkan wilayah Manado, Minahasa, dan Tomohon serta mendukung pertumbuhan ekonomi di Sulawesi Utara, maupun daerah sekitarnya.

4. Adanya pemukiman berupah bangunan rumah tinggal, restoran, resting area, dan hotel di sepanjang jalan Tomohon Manado merupakan perubahan tata guna lahan, lokasi tersebut terletak di lereng bukit yang terjal, rawan terhadap bencana tanah longsor.

5. Pemerintah Kota Tomohon sudah berupaya membatasi pemanfaatan ruang di kawasan rawan bencana terhadap kegiatan pemukiman. Namun kenyataannya, masih ada pemanfaatan lahan di daerah rawan tanah longsor dan pemerintah daerah belum dapat menerapkan kebijakan tersebut secara optimal, hal tersebut dikarenakan sebagian besar penduduk sudah lama bermukim di daerah rawan bencana bahkan sudah ada yang turun-temurun.

6. Berdasarkan bentuk dan struktur topografi lokasi jalan Tomohon Manado, pemanfaatan lahan tidak layak untuk membangun rumah tinggal, restoran, resting area, dan hotel, karena sangat mempengaruhi ketidakstabilan lereng sehingga dapat mengurangi daya dukung tanah.

\section{Saran}

1. Diperlukan data penyelidikan lapangan yang lebih lengkap agar dapat menggambarkan kondisi riil di lapangan.

2. Perlu upaya mengurangi kerentanan masyarakat dalam pemanfaatan lahan 
M. S. S. S. Tumanduk ${ }^{1}$, T. U. Y. Pangkey ${ }^{2}$, Jurnal Sains dan Teknologi, Universitas Negeri Manado

pada daerah rawan bencana tanah longsor lewat sosialisasi.

3. Pemerintah Kota Tomohon harus tegas membatasi pemanfaatan ruang di kawasan rawan bencana terhadap kegiatan pemukiman.

\section{DAFTAR PUSTAKA}

Anonim, Pengenalan Gerakan Tanah, www.esdm.go.id/batubara/doc, download tanggal 27 September 2011

Bowles, J. E., (1986). Sifat-sifat Fisis dan Geoteknis Tanah, Edisi ke 2, Terjemahan oleh Ir. Johan K. H., Erlangga, Jakarta, Indonesia.

Craig, R.F., (1987). Mekanika Tanah, Edisi ke 4, Erlangga, Jakarta. Indonesia.

Hansen, M.J., (1984). Strategies for Classification of Landslides, (ed.:Brunsden, D, \& Prior, D.B., 1984), Slope Instability, John Wiley \& Sons, New York, USA.

Hardiyatmo, H.C., (2006). Penanganan Tanah Longsor dan Erosi, Gadjah Mada University Press, Yogyakarta, Indonesia.

Jayadinata, J.T. (1999). Tata Guna Tanah dalam Perencanaan Pedesaan Perkotaan dan Wilayah. Bandung : Penerbit ITB.

Karnawati, D. (2003). Manajemen Bencana Gerakan Tanah. Diktat Kuliah. Yogyakarta : Jurusan Teknik Geologi, Universitas Gadjah Mada.

Kuswanda, Wahyu P (2010) Penggunaan Bahan Geosintetik Untuk Rekonstruksi Tanah Longsor, Proceding Seminar Nasional
"Penanggulangan Bencana Alam di Berbagai Daerah di Indonesia" pada tanggal 8 Mei 2010, KMTS FT UGM, Yogyakarta .

Seyhan, E. (1990). Dasar-dasar Hidrologi. Terjemahan Sentot Subagyo. Yogyakarta : Gadjah Mada University Press.

Suripin, (2002). Pelestarian Sumberdaya Tanah dan Air. Yogyakarta : Penerbit Andi.

Suryolelono, K. B., (2004). Perancangan Fondasi, Nafiri, Yogyakarta, Indonesia. 